\title{
Use of Antimicrobial and Genotoxicity Potentiality for Evaluation of Essential Oils as Food Preservatives
}

\author{
Hend A. Hamedo*,1 and Hala M. Abdelmigid ${ }^{*, 2}$ \\ ${ }^{I}$ Faculty of Education, Suez Canal University, El Arish, Egypt \\ ${ }^{2}$ Faculty of Science, Botany Dept., Mansoura University, Egypt
}

\begin{abstract}
In this study, investigations were carried out to assess the efficiency of two plant essential oils; rosemary and oregano as natural food preservatives. The effect of the plant essential oils at concentrations of $0.1 \%, 0.5 \%$ and $1 \%$ was studied in the soft cheese against Salmonella enteritidis and Escherichia coli at fridge temprature over a 14-day period. The essential oils performed well in the inhibition of S. enteritidis and E. coli. It is concluded that selected plant essential oils can act as potent inhibitors of both microorganisms in a food product. At the same time, evaluation of their safety as food preservatives was undertaken via monitoring the genotoxic activity of the mentioned essential oils using Vicia faba test. Vicia faba roots were treated with the above concentrations for 3 hours. Results revealed cytotoxic and genotoxic effects of the applied doses. Mitotic index decreased significantly when compared to control. Chromosomal abnormalities and micronuclei were also observed and the effects were dose-dependent. Despite the efficient role of the studied oils as antimicrobial agents, their genotoxicity potential in eukaryotic cells made them unacceptable as food preservatives, particularly at high doses. Therefore, more research in the use of essential oils as food preservatives is needed.
\end{abstract}

Keywords: Antimicrobial activity, Salmonella enteritidis, Escherichia coli, natural food preservative, rosemary oil, oregano oil, genotoxicity, Vicia faba test.

\section{INTRODUCTION}

In spite of modern improvements in food production techniques, food safety is still an important aspect of public health. It has been estimated that as many as $30 \%$ of people in industrialized countries suffer from a foodborne disease each year [1]. Salmonellosis was the most occurring bacterial foodborne disease, with more than 325,000 cases per year [2]. There is a worldwide trend to explore new alternatives to control foodborne diseases, giving priority to methods that reduce disease incidence and avoid negative and side effects on human health. Western society is experiencing a trend of "green" consumerism, desiring fewer synthetic additives in foods together with their increased safety and quality [3]. The use of phytochemicals as natural antimicrobial agents is gaining popularity [4]. Since there is growing interest in correlating phytochemical constituents of plant with its pharmacological activity [5], a rapidly growing market for antioxidants and preservatives based on natural plant extracts has arisen, as opposed to artificially produced antioxidants, this is due in part to health concerns regarding artificial additives.

Certain plants and their extracts which are used as flavoring agents possess antimicrobial activity and hence offering a potential alternative to synthetic preservatives [6]. Essential oils (EOs) from an estimated 3000 plant species are known, of which about 300 are commercially important -

*Address correspondence to these authors at the Faculty of Education, Suez Canal University, El Arish, Egypt; E-mail: hend_hamedo@hotmail.com

Faculty of Science, Botany Dept., Mansoura University, Egypt;

E-mail: halaabdelmigid@yahoo.com

Present address: King khaled university, Abha, KSA, P.O. 3340 destined chiefly for the flavors and fragrances market [7]. A few EOs are already commercially available as food preservatives in the form of sodium citrate and sodium chloride solutions, respectively [8]. Rosemary (Rosmarinus officinalis) is widely used as a culinary herb, especially in Mediterranean dishes, and is also used as a fragrant additive in soaps and other cosmetics. Recently, rosemary has been the object of laboratory and animal studies investigating its potential in the prevention of cancer and its antibacterial properties [9]. Most evidence for rosemary's medicinal uses comes from clinical experience rather than from scientific studies. Oregano (Origanum vulgare) has been used also for medicine and food preservation for thousands of years. A large number of in vitro, or in vivo studies, proved oregano oil, or its most active constituents carvacrol and thymol, as antimicrobial agents for a broad range of bacteria and fungi [10].

However, contrary to popular belief, approval of a natural food ingredient may not be as simple a process as one might think. In fact, unless an ingredient had a history of use in food prior to January 1, 1958, or the substance was deemed "safe by scientific procedures", the ingredient must be determined Generally Recognized As Safe (GRAS) or be classified as a food additive. Furthermore, approval for one use (such as a flavor) does not constitute approval for any other use [11]. A number of EOs components have been registered by the European Commission for use as flavorings in foodstuffs (Commission Decision of 23 January, 2002). The registered flavorings are considered to present no risk to the health of the consumer. Essential oil safety has been monitored in a variety of different ways, all of which have been geared to the perfumery, cosmetics and the food industries [12]. The whole aspect of safety is now being stringently 
reviewed and new regulations may soon impede the sale and usage of many essential oils as well as their use in foods. Proof of absolute safety does not exist, because nothing is absolutely devoid of risk. Essential oils may also contain low or high concentrations of toxic constituents [13].

With the increasing concerns on genotoxicity of environmental pollutants on living cells, there are about a dozen reliable, some even unique, plant genetic systems that can increase the scope and effectiveness of chemical and physical mutagen screening and monitoring procedures [14]. There are several major advantages of the plant test systems which relate to their reproductive nature, easy culture and growth habits that should be considered in mutagen screening and monitoring. In addition to these advantages, several plant test systems including Vicia faba test exhibit numerous genetic and chromosome changes for determining the effects of mutagens. Some of these have not yet been detected in other nonmammalian and mammalian test systems, but probably occur in the human organism. Plants have played major roles in various aspects of mutagenesis research, primarily in mutagen screening (detection and verification of mutagenic activity), mutagen monitoring, and determining mutagen effects and mechanisms of mutagen action. For the previously mentioned reasons many research Programs [e.g. the Program of the Committee on the Mutagenicity of Chemicals in food, consumer products and the environment (COM)] recommends as a preliminary study, a short-term tests in vitro and/or in vivo, for monitoring and testing potential mutagens. In this study, a preliminary assessment of the genotoxicity assay was undertaken via the use of a plant model system, represented by the root tip meristems of Vicia faba. It has six pairs of large chromosomes, easy to grow and does not require any sterile conditions so it is easy to observe chromosomal aberrations with this system [15].

The main goal of this study was to evaluate the efficacy of some commercially available plant essential oils as antimicrobial agents, and to investigate their safety by monitoring their genotoxicity effects on eukaryotic cells represented by Vicia faba cells. Based on previous study, essential oils of oregano and rosemary were chosen for assessment. They were screened against Salmonella choleraesair and Escherichia coli at different doses using in vitro test. One of the objectives of this study was to create comparable antimicrobial data between in vitro study and a real food system represented by soft cheese.

\section{MATERIALS AND METHODS}

\section{Preparation of Essential Oils}

The volatile oil of rosemary (Rosmarinus officinalis) and oregano (Origanum vulgare) were extracted from the above ground air dried parts (Shoot system) using steam-distillation apparatus for 3 hours. The oils obtained were separately dried over anhydrous sodium sulphate [16].

\section{Microbial Strains and Culture Conditions}

The essential oils were individually tested against the two microorganisms, Escherichia coli and Salmonella enteritidis. These strains were obtained from Laboratory of Bacteriology, Department of Botany, Faculty of Science, Ismaillia University. The Bacteriological agar and nutrient broth were from Difco.

\section{Antimicrobial Activity Test}

The soft cheese was purchased from a market. The packaging showed the absence of artificial preservatives. Preliminary experiments in which nutrient agar plates were inoculated with cheese at $1 / 10$ dilution and incubated at $37^{\circ} \mathrm{C}$ for $48 \mathrm{~h}$, exhibited no microbial contamination of this product. The used procedure was based on that of [17], $10 \mathrm{~g}$ of cheese was added to $90 \mathrm{ml}$ of phosphate buffered saline (PBS) which was prepared in the laboratory, and homogenized for $2 \mathrm{~min}$. Plant essential oils of Rosmarinus officinalis and Origanum vulgare were added to the cheese mixture to achieve final concentrations of $0.1,0.5$ and $1 \%$. PBS was used as control. The mixture of the plant essential oil with the cheese was homogenized for a further $30 \mathrm{~s}$ to ensure even mixing. The cheese mixture was inoculated with $100 \mu \mathrm{l}$ of $S$. enteritidis or E. coli cultures, then mixed thoroughly with the cheese mixture by gently squeezing the bags by hand and the concentration of both organisms in the cheese determined at 0 hours and 1, 2, 3, 7, 10 and 14 days using the serial dilutions and spread plate technique [18].

\section{Genotoxicity Test}

In this study, Vicia faba $(2 \mathrm{n}=12)$ seeds were used as the test system. Two essential oils of rosemary and oregano were used as the test substance. Seeds of Vicia faba were obtained from commercial market. They were soaked in tap water for 24 hours at $25^{\circ} \mathrm{C}$ and allowed to germinate in moist perlite in the dark for 4 days at $25^{\circ} \mathrm{C}$. At this time, seedlings were grown $3-5 \mathrm{~cm}$ long primary roots which is a suitable length to be used in the experiments. The primary roots were treated with the prepared essential oils at the concentrations of $0.1 \%, 0.5 \%$ and $1 \% \mathrm{v} / \mathrm{v}$ for 3 hours. Essential oils were diluted with phosphate buffer (PBS). PBS was used as control. Roots of both control and treated seeds were fixed in ethanol: acetic acid (3:1), stained with aceto-carmine and squashed in $45 \%$ acetic acid. Slides were made permanent, mounted in Canada balsam, examined, and photographed.

The mitotic index (MI) and chromosome aberrations were determined by examination of 1000 cells in five or six root tips. To determine cytotoxicity, the cytotoxic limit value was calculated from the MI [19-21]. Genotoxicity was assessed by observing chromosome aberrations in mitotic cells and they were classified in the following categories: bridges, micronuclei and stickiness. Also, micronuclei in the interphase nucleus were scored in 1000 cells of five or six root tips.

\section{Reproducibility and Statistical Analysis}

Antimicrobial activity experiments were conducted in triplicate on three separate occasions. Due to the limitations of the serial dilution technique, it was not possible to determine cfu of less than $1 \log _{10} \mathrm{cfu} \mathrm{ml} \mathrm{m}^{-1}$. Analysis of variance of data was performed with SPSS. To determine statistical significance of data, one-way ANOVA test was used. Table 1 indicates significant variation $(\mathrm{P}<0.05)$ in mitotic indices (MI) and aberrations comparing the normal and aberrant cells at each concentration with control.

\section{RESULTS AND DISCUSSION}

\section{Antimicrobial Activity}

The antimicrobial activity of EOs has been extensively studied and demonstrated against a number of microorgan- 
(a)

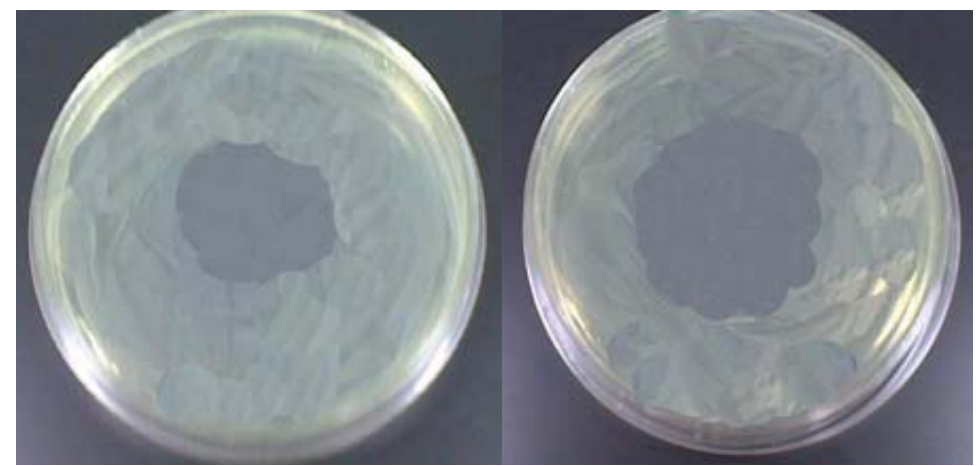

(b) (b)

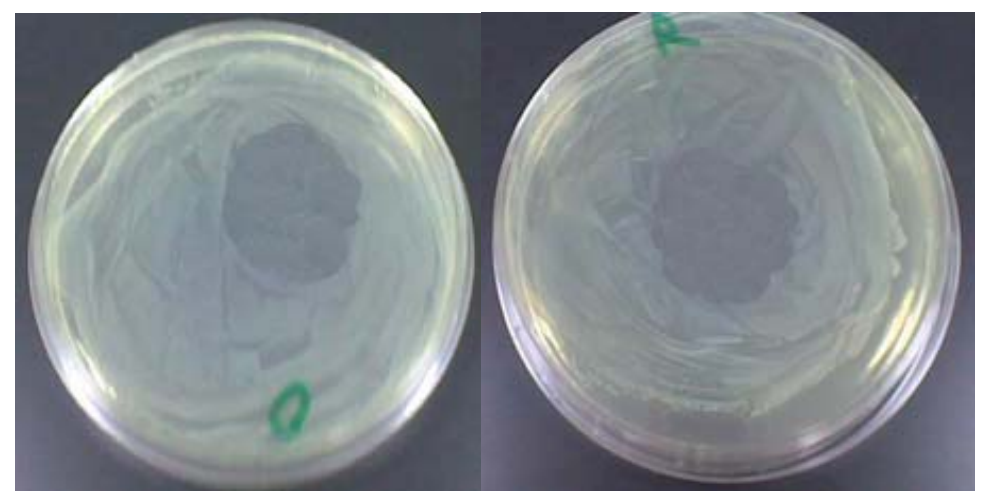

Fig. (2). Inhibition of E. coli by oil of oregano (a) and rosemary (b).

isms, usually using a direct-contact antimicrobial assays, such as different types of diffusion [7]. The studied essential oils showed various degrees of inhibition (Figs. 1, 2) against the two bacterial strains using the drop diffusion method [22].

The present data exhibited the potential of plant essential oils as natural food preservatives against Salmonella enteritidis and Escherichia coli in full-fat soft cheese. It should be taken into consideration that the inhibition reported here was for $1 / 10$ diluted cheese and therefore may not be a true reflection of inhibition achieved in cheese, but was necessary due to practical considerations. Despite this, the research showed the potential application of plant essential oils as natural food preservatives.

With respect to food contamination with foodborne pathogens, both rosemary and oregano oils revealed their suitability in this conern. Concentration of $0.1 \%$ performed well in the inhibition of the two organisms (Figs. 3, 4). The two oils reduced the growth of $E$. coli $\leq 3.8 \log _{10} \mathrm{cfu} \mathrm{ml}^{-1}$ after 3 days. In comparison, rosemary oil reduced the growth of $S$. enteritidis to $\leq 3.8 \log _{10} \mathrm{cfu} \mathrm{ml}^{-1}$ after 3 days, while oregano oil reduced its growth to $\leq 4.4 \log _{10} \mathrm{cfu} \mathrm{ml}^{-1}$ after 7 days (Figs. 5, 6).

At the concentration of $0.5 \%$, rosemary oil proved to be more effective against $S$. enteritidis and $E$. coli in soft cheese. The oil reduced the growth to $\leq 3.9 \log _{10} \mathrm{cfu} \mathrm{ml}^{-1}$ and to $\leq 3.1 \log _{10} \mathrm{cfu} \mathrm{ml}^{-1}$ after 3 days for $S$. enteritidis and
E. coli respectively. In case of oregano oil the growth of $S$. enteritidis was reduced to $\leq 3.7 \log _{10} \mathrm{cfu} \mathrm{ml}^{-1}$ and the growth of $E$. coli was reduced to $\leq 3.2 \log _{10} \mathrm{cfu} \mathrm{ml}^{-1}$ after 3 days. At the concentration of $1 \%$ both oils reduced the growth of $S$. enteritidis in the cheese to $\leq 2.6 \log _{10} \mathrm{cfu} \mathrm{ml}^{-1}$ for rosemary and to $\leq 2.9 \log _{10} \mathrm{cfu} \mathrm{ml}^{-1}$ for oregano after just 2 days. On the other hand, rosemary oil reduced the growth of $E$. coli to $\leq 1.9 \log _{10} \mathrm{cfu} \mathrm{ml}^{-1}$ after 3 days only, while the oregano oil reduced the growth of $E$. coli to $\leq 2.1 \log _{10} \mathrm{cfu} \mathrm{ml}^{-1}$ after 7 days. All results showed significant growth inhibition of both organisms in the soft cheese $(\mathrm{p} \leq 0.05)$.

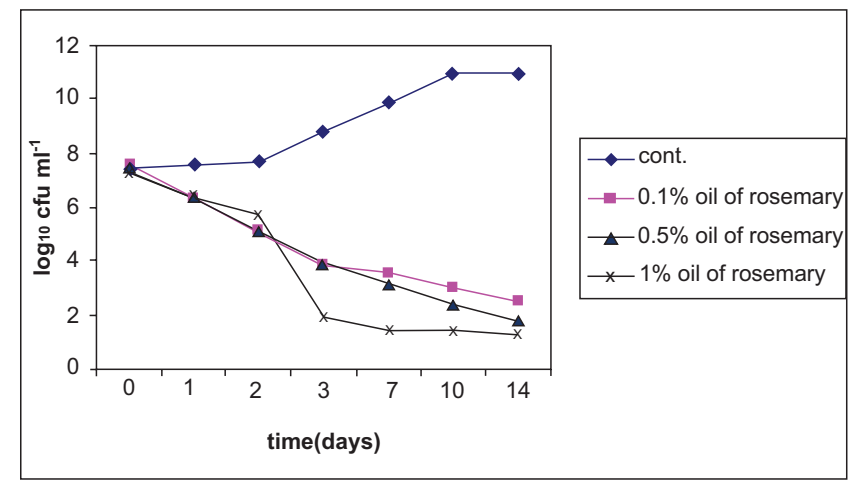

Fig. (3). Inhibition of E. coli in soft cheese by oil of rosemary. 


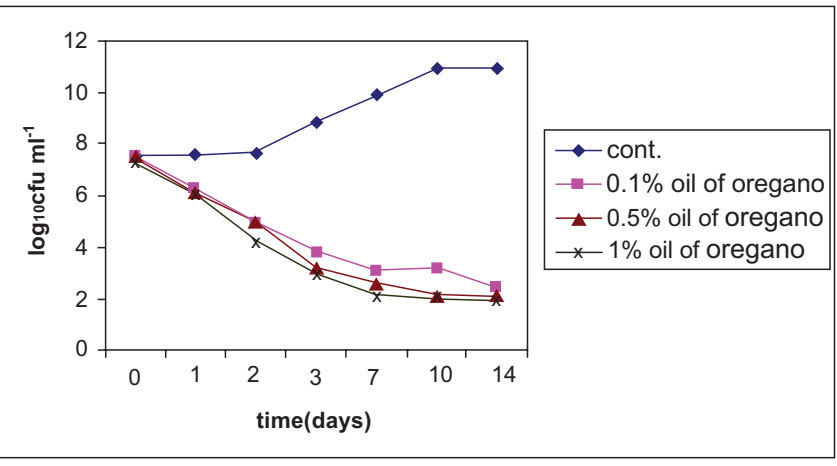

Fig. (4). Inhibition of E. coli in soft cheese by oil of oregano.

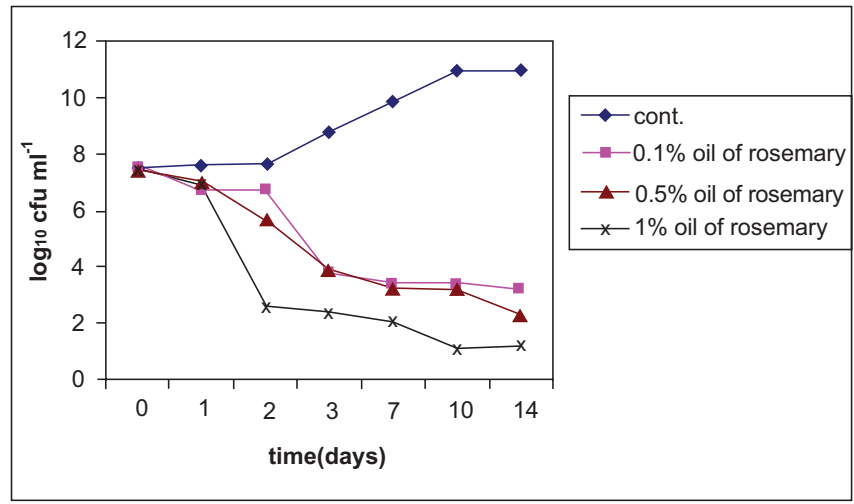

Fig. (5). Inhibition of $S$. enteritidis in soft cheese by oil of rosemary.

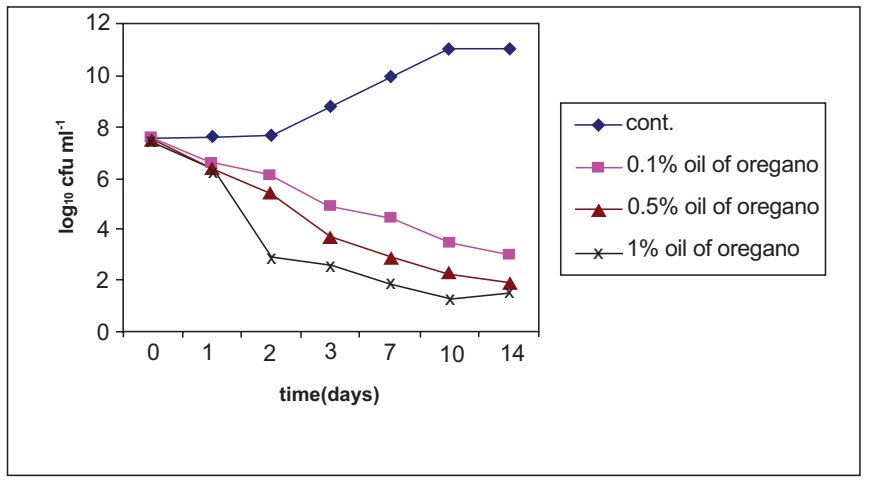

Fig. (6). Inhibition of S. enteritidis in soft cheese by oil of oregano.

Concentrations of $0.1 \%, 0.5 \%$ and $1 \%$ of these plant essential oils were required to achieve inhibition in food. However, it has been suggested that essential oils at concentrations of less than $0.1 \%$ had previously proved bactericidal effect in laboratory media [23]. In this study we used products contaminated with a higher inoculum than should be encountered in naturally contaminated products. Thus, lower concentrations of oils might suffice for naturally contaminated products.

The need to use plant essential oils at higher concentrations in food than in laboratory media is believed to be due to the more complex growth environment in food. This pro- vides microbial cells with greater protection from antimicrobial agents. It has been reported that the fat in food could form a protective coat around bacteria, thereby protecting them from antimicrobial agents [24]. The lipid fraction of the food has been suggested to absorb the antimicrobial agent, thus decreasing the concentration in the aqueous phase and hence its bactericidal action. Furthermore, the reduced water content in food compared to laboratory media could hamper the transfer of antimicrobial agents to the active site in the microbial cell.

A number of products which poses foodborne problems should be stored under refrigeration conditions $\left(2-4^{\circ} \mathrm{C}\right)$, hence limiting bacterial growth. The data presented here showed the potential of selected plant essential oils as potent inhibitors of $S$. enteritidis and E. coli in dairy products. This is especially relevant at a time when there is an increasing interest in finding more natural alternatives to many existing preservatives. By using essential oils as food preservative, a stable and, safe cheese may be produced with low, if any, loss in sensory quality [25].

\section{Genotoxicity Potential of Essential Oils}

There is little clinical information for many essential oils regarding the use of such oils in foods, extrapolation from constituent data is often undertaken. However, this can result in misleading conclusions. The presence of carcinogens in essential oils should not be ignored, and this remains an area where risk has not been clearly determined [26, 27]. In this case, the toxicity of whole essential oils should be under consideration, and the case for constituent extrapolation is poor.

Several in vitro genotoxicity studies were performed in both prokaryotic and eukaryotic test systems with rosemary and oregano extracts. However, these studies did not give rise to safety concerns with respect to genotoxicity of these two plant extracts [28]. Genotoxic effects of the above mentioned essential oils on the meristematic cells of Vicia faba root tips in different doses are given in Table $\mathbf{1}$ and Fig. (7b).

Inhibition of mitotic activities is often used for tracing cytotoxic substances [29]. Mitotic index (MI) can be used as a parameter of cytotoxicity by evaluating cell division frequency. Both rosemary and oregano oils decreased the MI in the treatment group at all concentrations. The decreasing of the MI was dose-dependent in the 3-hour treatment period. With regard to MI values in Table $\mathbf{1}$ it is clear that the reduction in mitotic activity caused by oregano oil was more pronounced than that caused by rosemary oil. Application of $0.1 \% \mathrm{v} / \mathrm{v}$ doses caused significant decrease in mitotic index of Vicia faba when compared with control. According to the cytotoxic limit values (Table 1) both oils exhibited sublethal cytotoxic effects [21]. Application of $0.5 \%$ and $1 \% \mathrm{v} / \mathrm{v}$ doses caused a hardness of the meristematic tissue and almost only non dividing cells were observed so that MI values on those doses could not be estimated. Mitotic inhibition caused by different chemicals can be related with an increase in G2 period [15]. According to our findings, excessive application of both oils has such an effect.

In addition to the previous cytotoxic effects of rosemary and oregano oils, they caused genotoxic effects in the mitotic cells represented by some chromosomal and nuclear irregu- 
Table 1. The Mitotic Index (MI\%); Mitotic Chromosomal Abnormalities (MCA\%); Interphase Nuclear Abnormalities (INA\%), in Vicia Cells Treated with Oregano and Rosemary Oils. $\mathbf{P}<0.05$

\begin{tabular}{|c|c|c|c|c|c|}
\hline I.N.A.\% & M.C.A.\% & Cytotoxic Limit Value & MI\% & Conc. & Treatment \\
\hline \hline 2.28 & 4.08 & - & 17.2 & $0.1 \%$ & Control \\
\hline $2.24^{\mathrm{b}}$ & $21^{\mathrm{b}}$ & $50.5 \%$ & $8.7^{\mathrm{a}}$ & - & $0.5 \%$ \\
- & - & - & - & $0.1 \%$ & $0.1 \%$ \\
- & - & - & $6.9^{\mathrm{a}}$ & $0.5 \%$ \\
\hline $3.54^{\mathrm{b}}$ & $55.7^{\mathrm{a}}$ & $40.1 \%^{\mathrm{a}}$ & - & $1 \%$ \\
\hline
\end{tabular}

asignificant.

bonsignificant.

$\mathbf{a}$

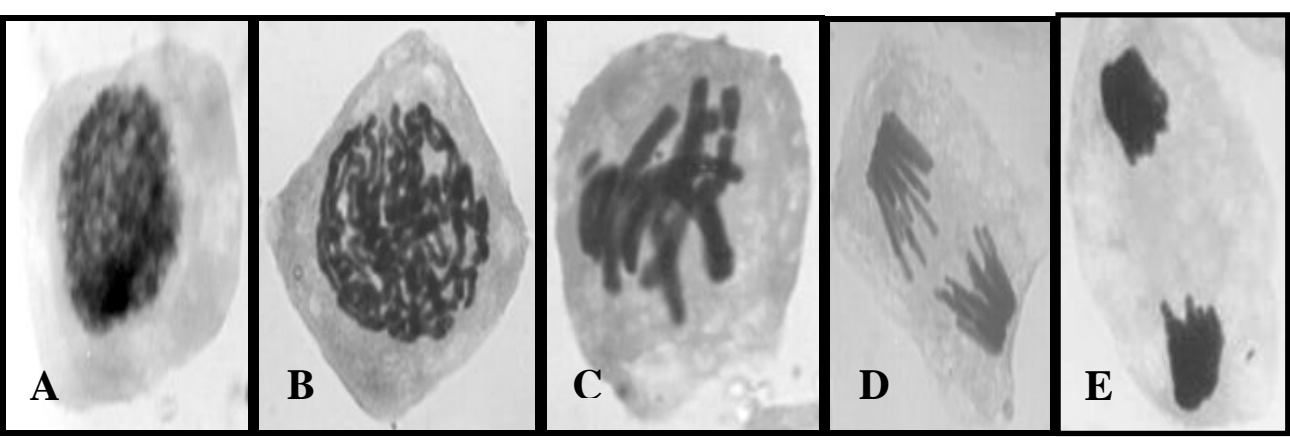

b

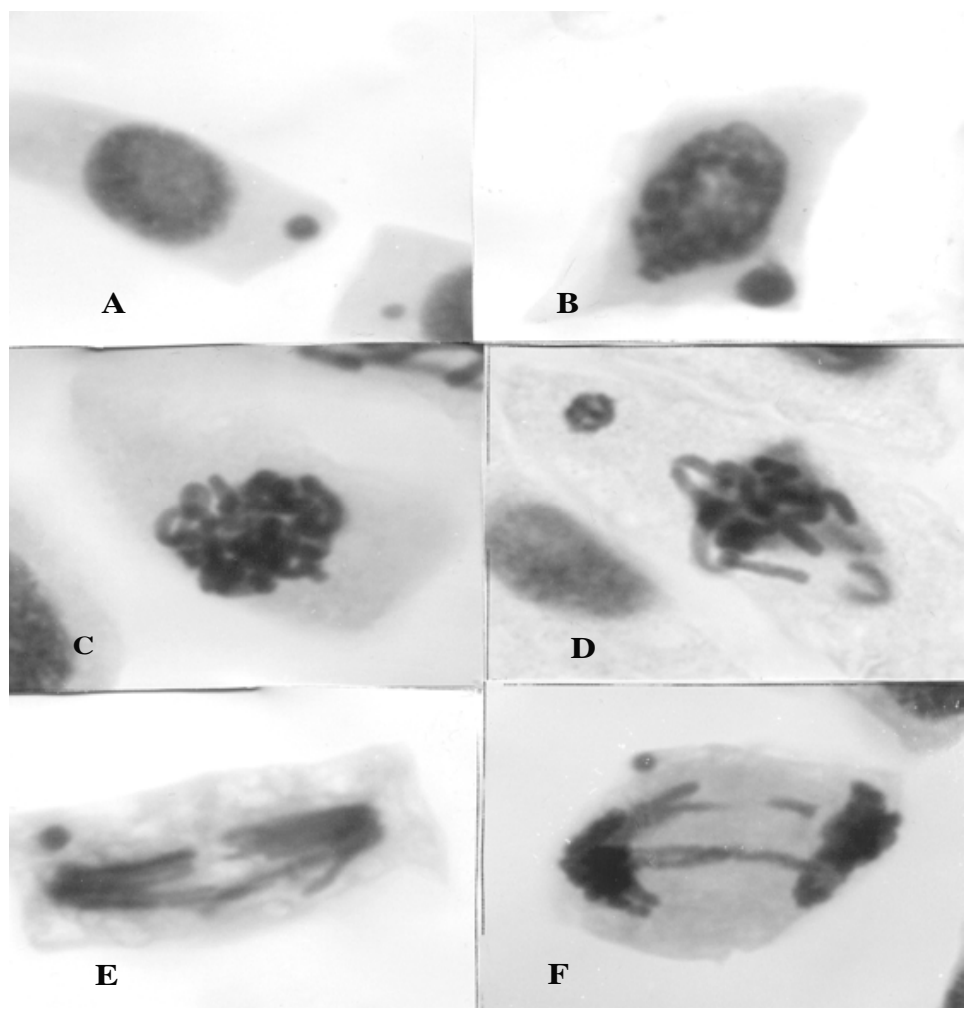

Fig. (7) a: Normal mitotic stages in Vicia cells (control), A: interphase; B: prophase; C: metaphase; D: anaphase; E: telophase b: Nuclear and chromosomal abnormalities induced by rosemary and oregano oils $(0.1 \%)$ in Vicia cells. A: Micronucleus in interphase; $\mathbf{B}$ : Micronucleus in prophase C: Stickiness in prophase; D: Stickiness and micronucleus in metaphase; E: bridge and micronucleus in Anaphase; F: bridge and micronucleus in telophase. 
larities. It is clear from Table $\mathbf{1}$ that the increasing of these two kinds of abnormalities and the percentage of abnormal cells was dose-dependent. Application of $0.1 \%$ of oregano oil caused significant increase in chromosomal aberrations compared to control (Fig. 7a). On the other hand, rosemary oil caused nonsignificant increase in those aberrations at the same concentration. Thus, oregano oil exhibited higher genotoxic effect than rosemary oil. Application of $0.5 \%$ and $1 \%$ doses caused dramatic genotoxic effects which made the scoring of both kinds of abnormalities difficult. Most observed chromosomal aberrations (Fig. 7B-F) were; chromosomal stickiness, anaphase and telophase bridges and formation of micronuclei. Similar results were obtained by using other tests [12]. Chromosomal aberrations formed by application of the studied oils are similar to aberrations formed by other chemical mutagens. Anaphase bridge formation is a result of dicentric chromosomes and chromosomal stickiness. Stickiness occurs as a result of subchromatic bridges [15]. Effects of chemicals on spindle apparatus cause some abnormalities such as; stickiness, multipolar anaphase, chromosome bridges and unequal chromosome distributions [30]. Application of oils in $0.1 \%$ doses of both oils caused nonsignificant increase in the formation of micronucleus in interphase nucleus (Fig. 7A). Micronucleus formation is the result of acentric fragments or laggers being excluded from nucleus during mitosis [31]. They are small cytoplasmic substances, which are formed as a result of chromosome breaks and aneuploidy during cell division [32]. Micronucleus formation is considered to be one of the most economical, quickest and most effective way in determining genotoxicity of different chemicals [31]. In conclusion, both oregano and rosemary oils caused harmful effects on the root tip cells of Vicia faba.

Investigation results of essential oil genotoxicity are rather contradictory. Some reports indicated that essential oils of various plants were able to induce genetic damages in various test-systems. According to other authors, essential oil of such aromatic plants as Origanum vulgare did not show any genotoxic effect [12]. Essential oils from rosemary and oregano plants in the present investigation was active in meristematic cells of Vicia faba and increase the frequency of abnormal cells. Several international research programs (e.g., The International Program of Chemical Safety) recommend Vicia as a rapid economical and reproducible test system [33]. The genotoxicity test showed that all tested oils induce both cytotoxic and genotoxic effects, in Vicia faba root meristem cells. The reduction in mitotic activity and the high percentage of chromosome and nuclear irregularities in the meristematic cells of Vicia, suggests the presence of certain cytotoxic/genotoxic substances in the tested oils.

\section{CONCLUSION AND RECOMMENDATIONS}

This study comes at a time when plant-based alternatives to chemical preservatives are increasing in popularity, even to the point that the synthetic antioxidant market is in decline while the natural antioxidant market is growing. Antimicrobial results from the present study agree with those obtained previously, denoting even the possibility of replacing synthetic antioxidants such as BHT with natural extracts with antioxidant activity obtained from plants. While the study results suggest that natural alternatives to synthetic preservatives are viable, some obstacles still remain. Regardless of the costs, the main challenges of using these substances on food products are related to safety concern. The previous toxicological data on the rosemary and oregano oils are insufficient to establish a numerical ADI (Amount Daily Intake) because it does not provide reproductive toxicity studies or a long term study. On the other hand, the existing genotoxicity data in this study, concluded that the proposed uses and use levels would not be of safety concern. Further genotoxicity, mutagenicity and pharmacological evaluations on both essential oils and components are needed. Also, it is essential to carry out experimental works to prove the effectiveness of these substances in every single product because their activity as antioxidants depends on a large number of factors, including the characteristics of the food. Further, we postulate that essential oils themselves at lower concentrations are likely more effective than the used concentrations. If this is further confirmed, then this is an excellent strategy to design the right natural food preservatives to attack foodborne bacterial pathogens in a food matrix without the risk of genotoxicity of human cells. In addition, the exact mechanisms of cellular damage by essential oils should be elucidated. This will be further investigated in our laboratory.

\section{REFERENCES}

[1] WHO. Food safety and foodborne illness. World Health Organization Fact sheet 237. Geneva: Switzerland 2002.

[2] Rocourt JG, Moy KV, Schlundt J. The present state of foodborne disease in OECD countries. WHO Document Production Services. Geneva, Switzerland 2003; p. 39.

[3] Bautista-Banos SA, Hernandez-Lauzardo MG, Velazquez-del Valle $\mathrm{M}$, et al. Chitosan as a potential natural compound to control pre and postharvest diseases of horticultural commodities. Crop Prot 2006; 25: 108-18.

[4] Smid EJ, Gorris LGM. Handbook of Food Preservation. Natural antimicrobials for food preservation. New York: Marcel Dekker 1999; pp. 285-308.

[5] Vaidya AB, Antarkar VDS. New drugs from medicinal plants, opportunities and approaches. J Assoc Physic India 1994; 42: 221-

[6] Gould GW. Industry perspectives on the use of natural antimicrobials and inhibitors for food applications. J Food Prot 1996; (Suppl): 82-6.

[7] Burt S. Essential oils: their antibacterial properties and potential applications in foods, a review. Int J Food Microbiol 2004; 94: 223-53.

[8] Cutter CN. Antimicrobial effect of herb extracts against Escherichia coli O157: H7, Listeria monocytogenes, and Salmonella typhimurium associated with beef. J Food Prot 2000; 63: 601-7.

[9] Slamenova D, Kuboskova K, Horvathova E, Robichova S. Rosemary-stimulated reduction of DNA strand breaks and FPGsensitive sites in mammalian cells treated with $\mathrm{H} 2 \mathrm{O} 2$ or visible light-excited Methylene Blue. Cancer Lett 2002; 177(2): 145-53.

[10] Lin YT, Labbe RG, Kalidas S. Inhibition of Listeria monocytogenes in fish and meat systems by use of oregano and cranberry phytochemical synergies. Appl Environ Microbiol 2004; 70(9): $5672-8$

[11] Casterton PL, Mozingo AC, Burdock GA. Approving preventatives: not a natural process. Acta Hortic 2006; (ISHS) 709: 23-8.

[12] Morkünas V. Investigation of the genetic toxicology of dill essential oil and benzo(a) pyrene in mouse bone marrow by micronucleus test. Biologija 2002; 4: 14-6.

[13] Tisserand R. Challenges facing essential oil therapy: proof of safety. Alliance of International Aromatherapists (AIA) Conference the AIA Board 2007.

[14] Nilan RA. Potential of plant genetic systems for monitoring and screening mutagens. Environ Health Perspect 1978; 27: 181-96.

[15] Koca S. The cytogenetic effects of sheffer A, a liquid fertilizer and growth regulator in root tip cells of ViciaFaba L. C.B.U. J Sci 2008; 4: 121-6. 
[16] Baratta MT, Dorman HJ, Deans SG, Figueiredo AC, Barroso JG, Ruberto G. Antimicrobial and Antioxidant properties of some commercial essential oils. Flavor Fragrance 1998; 13: 235-44.

[17] Back JP, Langford SA, Kroll RG. Growth of Listeria monocytogenes in camembert and other soft cheese at refrigeration temperatures. J Dairy Res 1993; 60: 421-9.

[18] Jay JM. Modern Food Microbiology, $4^{\text {th }}$ ed. NewYork: Chapman and Hall 1992

[19] Sharma CBSR. Plant meristems as monitors of genetic toxicity of environmental chemicals. Curr Sci 1983; 52: 1000-2.

[20] Panda BB, Sahu UK. Induction of abnormal spindle function and cytokinesis inhibition in mitotic cells of Allium cepa by the organophosphorous insectside fensulffothin. Cytobios 1985; 42: 14755.

[21] Antonsie-wiez D. Analysis of the cell cycle in the root meristem of Allium cepa under the influence of Leda krin. Folia Histochem Cytobiol 1990; 26: 79-96.

[22] Hili P, Evans CS, Veness RG. Antimicrobial action of essential oils: the effect of dimethylsulphoxide on the activity of cinnamon oil. Lett Appl Microbiol 1997; 24(4): 269-75.

[23] Smith-Palmer A, Stewart J, Fyfe L. Antimicrobial properties of plant essential oils and essences against five important food-borne pathogens. Lett Appl Microbiol 1998; 26: 118-22.

[24] Smith-Palmer A, Stewart J, Fyfe L. The potential application of plant essential oils as natural food preservatives in soft cheese. Food Microbiol 2001; 18: 463-70.

[25] Hayouni E, Imed C, Manaf A, et al. Tunisian Salvia officinalis L. and Schinus molle L. essential oils: their chemical compositions and their preservative effects against Salmonella inoculated in minced beef meat. Int J Food Microbiol 2008; 125: 242-51.
[26] Gardner I, Wakazono H, Bergin P, et al. Cytochrome P450 mediated bioactivation of methyleugenol to 1'-hydroxy methyleugenol in Fischer 344 rat and human liver microsomes." Carcinogenesis 1997; 18(9): 1775-83

[27] Jeurissen SM, Bogaards JJ, Awad HM, et al. Human cytochrome p450 enzyme specificity for bioactivation of safrole to the proximate carcinogen 1'-hydroxysafrole. Chem Res Toxicol 2004; 17: 1245-50

[28] European Food Safety. Scientific Opinion of the Panel on Food Additives, Flavorings, Processing Aids and Materials in Contact with Food on a request from the Commission on the use of rosemary extracts as a food additive. EFSA 2008; 721: 1-3.

[29] Linnainmaa K, Meretoja T, Sorsa M, Vainto SH. Cytogenetic effects of styrene and styrene oxide. Mutat Res 1978; 58: 277- 86.

[30] Badr A, Ibrahim AG. Effects of herbicide glean on mitosis, chromosomes and nucleic acids in Allium cepa and Vicia faba root meristems. Cytologia 1987; 52: 293-302.

[31] Ma TH, Zhidong Xu C, Mcconnel H, Rabago EV, Arreola GA Zhang $\mathrm{H}$. The improved Allium/Vicia root tio micronucleus assay for clastogenicity of environmental pollutants. Mutat Res 1995; 334: $185-95$

[32] Grisolia CK, Starling FL. Micronucleus monitoring of fishes from lake paranoa, under influence of seeewage treatment plant discharges. Mutat Res 2001; 491: 39-44.

[33] Sandhu SS, Serres FJ, Goplan HN, et al. Environmental Monitoring for genotoxicity with plant system Results and recommendations. Mutat Res 1994; 310: 257-63.

(c) Hamedo and Abdelmigid; Licensee Bentham Open.

This is an open access article licensed under the terms of the Creative Commons Attribution Non-Commercial License (http://creativecommons.org/licenses/by-nc/3.0/) which permits unrestricted, non-commercial use, distribution and reproduction in any medium, provided the work is properly cited. 